\title{
Impact of Tooth Surface Loss on the Quality of Life of Patients Seen in a Nigerian Teaching Hospital
}

\author{
Tunde Ogunrinde, Deborah Ajayi, Iyabo Abiodun-Solanke \\ University of Ibadan/University College Hospital, Ibadan, Nigeria \\ Email: tunde_ogunrinde2001@yahoo.com
}

How to cite this paper: Ogunrinde, T., Ajayi, D. and Abiodun-Solanke, I. (2020) Impact of Tooth Surface Loss on the Quality of Life of Patients Seen in a Nigerian Teaching Hospital. Open Journal of Stomatology, 10, 50-60.

https://doi.org/10.4236/ojst.2020.104007

Received: March 3, 2020

Accepted: April 7, 2020

Published: April 10, 2020

Copyright $\odot 2020$ by author(s) and Scientific Research Publishing Inc. This work is licensed under the Creative Commons Attribution International License (CC BY 4.0).

http://creativecommons.org/licenses/by/4.0/

\begin{abstract}
Background: Tooth surface loss (TSL) is a progressive process arising from erosion, abrasion, attrition or abfraction. It can affect individuals of any age group: children, young adult, adults or the elderly and can compromise the health of individual tooth or the entire dentition leading to poor quality of life of the affected person. Objective: To evaluate the pattern of TSL among dental patients in a Nigerian Teaching Hospital and to assess the impact of TSL on their quality of life. Subjects and Methods: The study was a cross-sectional study among patients with TSL in a Nigerian Teaching Hospital. The Oral Health Impact Profile-14 (OHIP-14) questionnaire was used to obtain information on the impact of TSL on the quality of life of the participants. Data collected were analysed using IBM SPSS version 20. Chi-square test was used to assess association between types of TSL and quality of life of the patients. Level of significance was set at $\mathrm{p} \leq 0.05$. Results: One hundred and twenty-five patients (Males $=72$; Females $=53$ ) with tooth wear lesions participated in the study. The most common type of tooth surface loss was attrition (40\%) followed by abrasion (23.2\%). The highest impact of TSL on the quality of life was painful sensation strongly affecting 39 (31.2\%) patients. This was followed by problem with chewing. There was no statistically significant relationship between patients' quality of life and types of tooth surface loss. Conclusion: The most common negative impact of TSL on patient quality of life was painful sensation.
\end{abstract}

\section{Keywords}

Quality of Life, Pattern, Tooth Wear

\section{Introduction}

Tooth surface loss (TSL) is a progressive phenomenon, arising from erosion, 
abrasion, attrition or abfraction. It may present as a normal physiological process occurring throughout life [1] (e.g. attrition) or as a gradual progressive pathologic process. It has a multifactorial cause and is rarely seen in isolation [2]. It can affect individuals of any age group: children, young adult, adults or the elderly [3]. The prevalence of TSL varies around the world. In Nigeria, a prevalence of 53\% was reported by Ibiyemi et al. [4] among rural dwellers in the southwest region of the Country while a study in Trinidad, West Indies by Rufeek et al., [5] reported a prevalence of $72 \%$ and a study among elderly population in Iraq [6] reported 100\% prevalence.

The health of individual tooth or the entire dentition can be compromised by tooth surface loss with manifestations ranging from dentine hypersensitivity to severe loss of tooth structure, abnormal occlusion and reduced facial height [7]. At the early stage of development, patients with tooth wear lesion may have no symptom, but if left untreated, it brings discomfort especially during eating, drinking or tooth brushing and this may progress to spontaneous pain or the pulp may become necrotic [8]. The patients seek help because of problems of pain, altered function and unsatisfactory appearance especially when the anterior teeth are involved [9].

The management of patients with TSL has caused great challenges for dental professionals for many years and the problem is on the increase due to the fact that more of the population is retaining their natural teeth into old age [10]. It was therefore the aim of this study to determine the patterns of tooth surface loss among adult patients who presented at the conservation unit of the Dental Centre of a Nigerian University Teaching Hospital and to assess the effects of tooth wear lesions on their quality of life.

\section{Material and Method}

The participants for this cross-sectional study were drawn from patients attending conservation clinic of the Dental Centre, in a Nigerian teaching Hospital. A convenience sampling method was adopted for the study. All consecutive patients that presented at the clinic with TSL during a period of one year (April 2017 to April 2018) and were willing to participate were recruited. After obtaining consent, the patients were assessed and examined clinically and those that satisfied the inclusion criteria were recruited into the study. The inclusion criteria were: willingness to participate, mental wellbeing and presence of TSL on any tooth. A self-administered questionnaire (Appendix 1) was used to obtain information from the participants. The questionnaire consisted of two parts. The first part asked about patients' age, gender, occupation, types of TSL and teeth affected. Patients were classified into five occupational groups using the modified classification of socio-economic strata devised by Famuyiwa et al:; [11] Class 1 included executive managers, bankers, large scale business men; Class 2: senior civil servants, Nurses, University and Polytechnic lecturers; Class 3: semi-skilled workers like artisans, junior civil servants; Class 4: unskilled workers, retiree and house wives, and class 5: students and the unemployed. The 
second part asked about the effect of TSL on oral health related quality of life using Oral Health Impact Profile-14 (OHIP-14) questionnaire. The OHIP-14 questionnaires consist of 14 questions subdivided into seven domains: functional limitations, physical discomfort, psychological discomfort, physical disabilities, psychological disabilities, social disabilities, and handicaps. For each question on the OHIP-14, the subjects were asked how frequently they had experienced the problem during the preceding 12 months. Responses were recorded using a 5-point Likert scale: $0=$ never, $1=$ hardly ever, 2 = occasionally, 3 = fairly often and $4=$ very often. Total OHIP score was calculated for each subject by adding the score for each question, while the mean score was calculated by dividing the total score by fourteen. The prevalence, extent and severity of oral health impact were calculated as suggested by Slade et al. [12]. Prevalence is the percentage of respondents reporting 1 or more "fairly often" or "very often." This variable identifies those whose oral health impacts are chronic rather than transitory; Extent is the number of items reported "fairly often" or "very often." while severity is the sum of the response codes for the 14 items (Total OHIP scores). The severity score can range from 0 to 56 , higher values indicating more frequent impacts. The OHIP questionnaire has been validated and found reliable in our environment (Lawal et al.) [13].

Oral examination was carried out in the dental clinic using probe and dental mirror with gloved hands by a calibrated senior resident doctor that was appointed for data collection. Prior to the recruitment of the patients and data collection, the criteria for categorizing the type of TSL into attrition, abrasion, erosion and abfraction were set out for him using the guidelines of Kelleher and Bishop [14].

Data were analyzed using IBM Statistical package for the social sciences (SPSS) version 20. Descriptive statistics, such as percentages, means and standard deviations, were used to describe basic information including sex, age, marital status, education level, occupation and type of tooth wear lesion. Chi-square test was employed to assess relationship between the outcome variable (total OHIP-14 scores) and socio demographic variables and types of tooth wear lesion. A p-value $<0.05$ was considered significant.

\section{Result}

Table 1 shows the socio-demographic characteristic of the patients. One hundred and twenty-five patients participated in the study. There were 72 (57.6\%) males and $53(42.4 \%)$ females. The age range was 15 to 90 years with a mean of 52.58 (17.84 S. D) years. The majority $54,(43.2 \%)$ were in the age range $41-60$ and $61-80$ years and $40(32 \%)$ of the respondents were low income earners, while 35 (28\%) were executive officers.

The most common type of tooth surface loss presented was attrition (40\%) followed by abrasion (23.2\%) while the least common was abfraction 6\% (Figure $1)$. 
Table 1. Socio-demographic characteristic of the patients.

\begin{tabular}{cccc}
\hline \multicolumn{2}{c}{ Socio demographic factor } & Frequency $(\mathrm{n})$ & Percentage (\%) \\
\hline \multirow{2}{*}{ Gender } & Male & 72 & 57.6 \\
& Female & 53 & 42.4 \\
& $21-40$ years & 15 & 12.0 \\
Age group & $41-60$ years & 54 & 43.2 \\
& $61-80$ years & 54 & 43.2 \\
& $>80$ years & 2 & 1.6 \\
& Group 1 & 35 & 28.0 \\
& Group 2 & 24 & 19.2 \\
Occupational group & Group 3 & 10 & 8.0 \\
& Group 4 & 16 & 12.8 \\
Group 5 & 40 & 32.0 \\
& & 125 & 100 \\
\hline
\end{tabular}

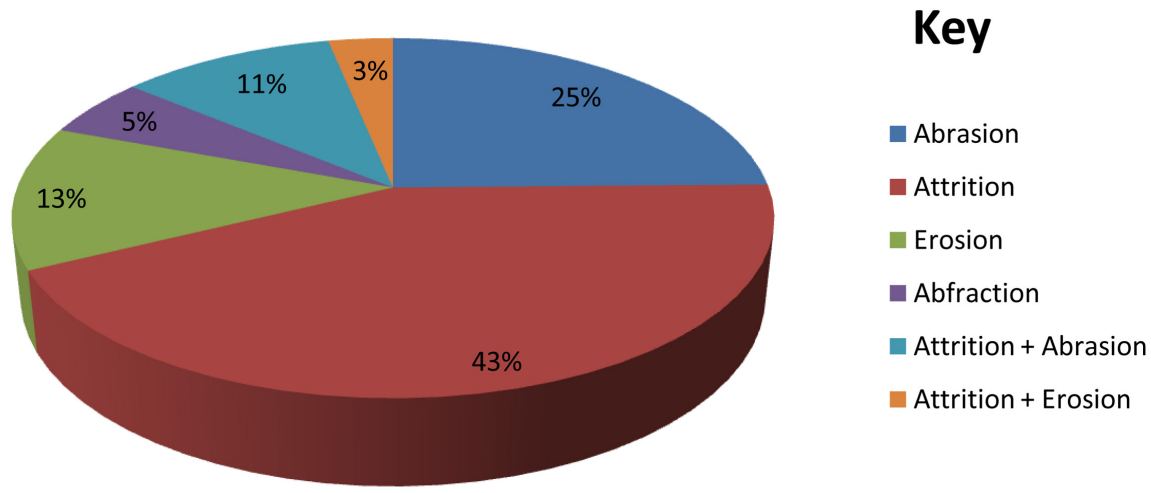

Figure 1. Distribution of types of tooth surface loss.

Table 2 shows the distribution of the items on OHIP with fairly often and very often responses. Fairly or very often responses by the patients were recorded for all items of the OHIP questions. However, painful sensation had the highest impact, 39 (31.2\%) patients in which $22(17.6 \%)$ and 17 (13.6\%) patients reported very often and fairly often respectively to the question: "Have you had painful aching anywhere in your mouth?" This was followed by problem with chewing $26(20.8 \%)$ in which $11(8.8 \%)$ and $15(12 \%)$ patients stated very often and fairly often respectively to the question "Have you had difficulty chewing any food because of problem with your teeth?" while the least impact, $1(0.8 \%)$ was for inability to perform usual function with the response very often $0(0 \%)$ and fairly often $1(0.8 \%)$ to the question "Have you been unable to perform the usual functions because of problems with your teeth?"

The severity of impact of TSL on quality of life of the patients ranged from 0 to 34 with a mean of 11.65 ( $S D=6.27)$, while the extent ranged from 0 to 7 and the prevalence of impact i.e. percentage of respondent reporting fairly often or very often for one or more items was $57.6 \%$, (Table 3 ). 
Table 2. Distribution of item on OHIP questionnaire with very/fairly often responses.

\begin{tabular}{|c|c|c|c|}
\hline \multirow[b]{2}{*}{ OHIP questions } & \multicolumn{2}{|c|}{ Patients with } & \multirow{2}{*}{$\begin{array}{c}\text { Total N } \\
(\%)\end{array}$} \\
\hline & $\begin{array}{c}\text { Very often } \\
\text { response } \mathrm{n}(\%)\end{array}$ & $\begin{array}{l}\text { Fairly often } \\
\text { response n (\%) }\end{array}$ & \\
\hline $\begin{array}{l}\text { a) Have you had difficult chewing any food } \\
\text { because of problem with your teeth? }\end{array}$ & $11(8.8)$ & $15(12)$ & $26(20.8)$ \\
\hline $\begin{array}{l}\text { b) Have you had trouble pronouncing any } \\
\text { words because of problems with your teeth? }\end{array}$ & $1(0.8)$ & $2(1.6)$ & $3(2.4)$ \\
\hline $\begin{array}{l}\text { c) Has your sense of taste been affected by } \\
\text { problems with your teeth? }\end{array}$ & $0(0)$ & $3(2.4)$ & $3(2.4)$ \\
\hline $\begin{array}{l}\text { d) Have you had painful aching anywhere } \\
\text { in your teeth? }\end{array}$ & $22(17.6)$ & $17(13.6)$ & $39(31.2)$ \\
\hline $\begin{array}{l}\text { e) Have you been self-conscious because of } \\
\text { your teeth? }\end{array}$ & $5(4)$ & $20(16)$ & $25(20)$ \\
\hline $\begin{array}{l}\text { f) Have you felt tense because of problems } \\
\text { with your teeth? }\end{array}$ & $2(1.6)$ & $2(1.6)$ & $4(3.2)$ \\
\hline $\begin{array}{l}\text { g) Has your diet been unsatisfactory } \\
\text { because of problems with your teeth? }\end{array}$ & $3(2.4)$ & $3(2.4)$ & $6(4.8)$ \\
\hline $\begin{array}{l}\text { h) Have you had to interrupt meals because } \\
\text { of problems with your teeth? }\end{array}$ & $2(1.6)$ & $2(1.6)$ & $4(3.2)$ \\
\hline $\begin{array}{l}\text { i) Have you found it difficult to relax } \\
\text { because of problems with your teeth? }\end{array}$ & $0(0)$ & $3(2.4)$ & $3(2.4)$ \\
\hline $\begin{array}{l}\text { j) Have you been embarrassed } \\
\text { because of your teeth? }\end{array}$ & $1(0.8)$ & $0(0)$ & $1(0.8)$ \\
\hline $\begin{array}{l}\text { k) Have you been a bit irritable with } \\
\text { other people because of your teeth? }\end{array}$ & $4(3.2)$ & $5(4.0)$ & $9(7.2)$ \\
\hline $\begin{array}{l}\text { 1) Have you had difficulty doing your } \\
\text { usual jobs (or attending school) because } \\
\text { of problems with your teeth? }\end{array}$ & $2(1.6)$ & $2(1.6)$ & $4(3.2)$ \\
\hline $\begin{array}{l}\text { m) Have you found life less satisfying } \\
\text { because of problems with your teeth? }\end{array}$ & $0(0)$ & $2(1.6)$ & $2(1.6)$ \\
\hline $\begin{array}{l}\text { n) Have you been unable to perform the } \\
\text { usual functions because of problems with } \\
\text { your teeth? }\end{array}$ & $0(0)$ & $1(0.8)$ & $1(0.8)$ \\
\hline
\end{tabular}

On domain mostly affected by TSL, physical pain domain had the highest mean, $3.10 \pm 1.52$ followed by functional limitation $2.14 \pm 1.50$ and the domain least affected was handicap domain with a mean score of $0.97 \pm 1.36$ (Table 4).

Table 5 shows the relationship between gender and total OHIP score: Higher proportion of females (47.2\%) when compare with males $(44.4 \%)$ had total OHIP score above the population mean. However, the relationship between patients' gender and impact of TSL on quality of life was not statistically significant $(\mathrm{p}=0.452)$. Also, the relationship between patients' ages and impact of TSL on quality of life was not statistically significant $(\mathrm{p}=0.763)$, though higher percentage $(53.3 \%)$ of patients in age group $20-40$ years had total OHIP scores that 
Table 3. Distribution of severity and extent of impact of TSL on quality of life of patients.

\begin{tabular}{ccc}
\hline Severity of impact & Frequency & Percentage \\
\hline $1-10$ & 57 & 45.6 \\
$11-20$ & 57 & 45.6 \\
$21-30$ & 10 & 8.0 \\
$>30$ & 1 & 0.8 \\
Total & 125 & 100 \\
\hline Extent of impact & Frequency & Percentage \\
\hline 0 & 54 & 43.2 \\
1 & 34 & 27.2 \\
2 & 23 & 18.4 \\
3 & 6 & 4.8 \\
4 & 6 & 4.8 \\
5 & 1 & 0.8 \\
7 & 1 & 0.8 \\
Total & 125 & 100 \\
\hline
\end{tabular}

${ }^{*}$ The severity of impact range from 0 to 34 with a mean of 11.65 (std $\left.=6.27\right) .{ }^{*}$ Seventy-one $(56.8 \%)$ had one or more items with very/fairly often responses given a prevalence of impact of $56.8 \%$.

Table 4. Distribution of OHIP scores according to domains.

\begin{tabular}{ccccc}
\hline OHIP DOMAINS & Min & Max & Mean & Standard Deviation \\
\hline Functional limitation & 0 & 6 & 2.14 & 1.50 \\
Physical pain & 0 & 7 & 3.10 & 1.52 \\
Psychological discomfort & 0 & 6 & 1.94 & 1.68 \\
Physical disability & 0 & 4 & 1.28 & 1.31 \\
Psychological disability & 0 & 5 & 1.50 & 1.45 \\
Social disability & 0 & 6 & 0.99 & 1.21 \\
Handicap & 0 & 6 & 0.97 & 1.36 \\
\hline
\end{tabular}

Table 5. Relationship between demographic variables and severity of impact of TSL on quality of life.

\begin{tabular}{ccccc}
\hline \multirow{2}{*}{$\begin{array}{c}\text { Gender and age } \\
\text { of participants }\end{array}$} & $\begin{array}{c}\text { Below mean } \\
(<11.65)\end{array}$ & $\begin{array}{c}\text { Above mean } \\
(>11.65)\end{array}$ & Total & $\begin{array}{c}\text { Chi-square test } \\
\text { (P-value) }\end{array}$ \\
\hline $\begin{array}{c}\text { Gender } \\
\text { Male }\end{array}$ & $\begin{array}{c}\text { To }(55.6 \%) \\
\text { Female }\end{array}$ & $32(44.4 \%)$ & $72(100 \%)$ & 0.452 \\
Age group & $28(52.8 \%)$ & $25(47.2 \%)$ & $53(100 \%)$ & \\
$20-40$ yrs & $7(46.7 \%)$ & $8(53.3 \%)$ & $15(100 \%)$ & \\
$41-60$ yrs & $29(53.7 \%)$ & $25(46.3 \%)$ & $54(100 \%)$ & 0.763 \\
$>60$ yrs & $32(57.1 \%)$ & $24(42.9 \%)$ & $56(100 \%)$ & \\
Total & $68(54.4 \%)$ & $57(45.6 \%)$ & $125(100 \%)$ & \\
\hline
\end{tabular}


were above the population mean.

Table 6 shows the relationship between type of TSL and total OHIP score: Greatest proportion of patients with erosion (53.3\%) had total OHIP scores above the mean (greater severity of impact) while the least proportion 6.7\%, were patients with abfraction. However, the relationship between types of TSL and severity of impact on quality of life was not statistically significant ( $\mathrm{p}=$ $0.534)$.

\section{Discussion}

TSL is a complex biological process with varying etiological factors. Various types have been identified which includes attrition, abrasion, erosion and abfraction [15]. Attrition is tooth wear resulting from tooth to tooth contact and is more prevalence in population where the diet has greater abrasive components and also in individual with parafunctional habits such as grinding and clenching habits [16]. Abrasion is tooth wear due to frequent contact of tooth surface with other hard substances such as hard tooth brushes, and abuse of dental scaling. Erosion is tooth surface loss resulting from biochemical action. It is more prevalent among people with gastric reflux, vomiting and high consumption of gastric juice [17].

Previous studies [5], [18] reported differences in the incidence of TSL in relation to the genders of the participants. In this study, the incidence of TSL is higher among male $(57.6 \%)$ than female. This is similar to the findings of Oginni and Olusile [18] that TSL is more prevalent among males in Nigeria. The reason for this could be that males are more involved in habits that result in tooth wear lesions such as clenching and grinding of teeth and also the possibility of males having higher bite forces than females [19].

This study also reveals that TSL affects individuals in all age groups but the prevalence is higher among middle age and the elderly. This is in agreement with the findings of higher incidence of TSL in the older age group by Ibiyemi et al. [4] and Taiwo et al., [20]. This is however, contrary to Rubby [21] report that it was more prevalent among patients less than 26 years old. The difference in

Table 6. Relationship between types of TSL and severity of impact on quality of life (total OHIP scores).

\begin{tabular}{ccccc}
\hline \multirow{2}{*}{ Types of TSL } & \multicolumn{2}{c}{ Total OHIP Scores } & Total & $\begin{array}{c}\text { Chi-square test } \\
\text { (P-value) }\end{array}$ \\
\cline { 2 - 4 } & $\begin{array}{c}\text { Below mean } \\
<11.65)\end{array}$ & $\begin{array}{c}\text { Above } \\
\text { mean }>11.65)\end{array}$ & & \\
\hline Abrasion & $15(51.7 \%)$ & $14(48.3 \%)$ & 29 & \\
Attrition & $29(58 \%)$ & $21(42 \%)$ & 50 & 0.534 \\
Erosion & $7(46.7 \%)$ & $8(53.3 \%)$ & 15 & \\
Abfraction & $5(83.3 \%)$ & $1(6.7 \%)$ & 6 & \\
Combination & $12(48 \%)$ & $13(52 \%)$ & 25 & 125 \\
Total & 68 & 57 &
\end{tabular}


the prevalence in relation to age in Rubby and our study could be due to dissimilarity in the predominant type of TSL in the two studies. Attrition which increases in prevalence with increase in age because of the cumulative effect of teeth contact was more prevalent in our study while erosion was predominant in Rubby's study [21].

The most common type of tooth surface loss presented in this study was attrition (40\%) and this is similar to result of previous studies in Nigeria [4] [18]. This is however, contrary to report of a study in Saudi-Arabia [22] and a European's study [23] in which erosion accounted for $90 \%$ and $70 \%$ of tooth surface loss respectively. The disparity in the findings could be due to differences in the main etiological factors of TSL in different part of the world. In this environment, the dietary habits of crushing bone, taking fibrous food and the use of chewing stick for oral hygiene care was a common practice [4] and this can be the reason for the predominant attrition type of TSL in this study.

Our findings show the prevalence of impact to be $57.6 \%$ and the highest impact of TSL (39) was on painful sensation followed by problem with chewing. Daly et al. [8] also reported painful sensation and discomfort as the most common negative effect of TSL on the quality of life of their patients. However, Bardsley [24] reported problem with aesthetic as most impact of TSL on quality of life of the population studied. Painful sensation was responsible for the highest impact on OHQL in this study possibly because of the poor dental awareness of the patients leading to late presentation in the clinic for treatment.

There was a greater impact of tooth surface loss among females than males and this could be due to the fact that females are more concerned about their oral health than males [25]. Also a higher proportion (53.3\%) of the patients in age group 20 - 40 years (young adult) had total OHIP score above the population mean indicating greater severity of impact of TSL in this age group than other. This might be explained that people in this age group are more critical about their quality of life, more concern with respect to their appearance and oral functions and less tolerant to changes in their dental status.

In this study, the domain least affected was handicap domain (which asks about patient's inability to perform usual functions and found life less satisfying because of TSL). This finding agreed with report of previous study that common dental diseases although have negative impact on quality of life of patients, it rarely incapacitate the patients [26].

A possible limitation in this study is failure to categorize tooth surface loss according to its severity. Severity of oral diseases has been reported to be closely related with the impact on quality of life of patients. Vargas-Ferreira et al. [27] reported that low levels of TSL severity did not cause pain or any other psychosocial discomfort for children and this was corroborated by Pires de Andrade et al. [28].

\section{Conclusion}

Attrition is the most common form of TSL in this study and TSL affected indi- 
viduals belonging to different age groups. The prevalence of impact of TSL on oral health quality of life was high. Pain and inability to chew were the major effects of TSL on oral health related quality of life.

\section{Conflicts of Interest}

The authors declare no conflicts of interest regarding the publication of this paper.

\section{References}

[1] Flint, S. and Scully, S. (1988) Orofacial Age Changes and Related Disease. Dental Update, 15, 337-340.

[2] Hemingway, C.A., Parker, D.M., Addy, M. and Barbour, M.E. (2006) Erosion of Enamel by Non-Carbonated Soft Drinks with and without Tooth Brushing Abrasion. British Dental Journal, 201, 447-450. https://doi.org/10.1038/sj.bdj.4814073

[3] Bishop, K.A., Briggs, P.F.A. and Kelleher, M.G.D. (1994) The Etiology and Management of Localized Anterior Tooth Wear in the Young Adults. Dental Update, 21, 153-161.

[4] Ibiyemi, O., Oketade, I.O., Taiwo, J.O. and Oke, G.A. (2010) Oral Habits and Tooth Wear Lesions among Rural Adult Males in Nigeria. Archives of Orofacial Sciences, 5, 31-35.

[5] Rafeek, R.N., Marchan, S., Eder, A. and Smith, W.A. (2006) Tooth Surface Loss in Adult Subjects Attending a University Dental Clinic in Trinidad. International Dental Journal, 56, 181-186. https://doi.org/10.1111/j.1875-595X.2006.tb00092.x

[6] Al-Azawi, M.G. and El-Samarrai, S.K. (2014) Distribution of Tooth Wear among Institutionalized Residents (50-89 Years Old) in Baghdad City/Iraq (Cross Sectional Study). Journal of Baghdad College of Dentistry, 26, 180-183. https://doi.org/10.12816/0015186

[7] Luo, Y., Zeng, X.J., Du, M.Q. and Bedi, R. (2005) The Prevalence of Dental Erosion in Preschool Children in China. Journal of Dentistry, 33, 115-121. https://doi.org/10.1016/j.jdent.2004.08.007

[8] Daly, R.W., Bakar, W.Z., Husein, A., Ismail, N.M. and Amaechi, B.T. (2010) The Study of Tooth Wear Patterns and Their Associated Aetiologies in Adults in Kelantan, Malaysia. Archives of Orofacial Sciences, 5, 47-52.

[9] Iberlson, R. and Eder, A. (1999) Tooth Surface Loss. Editors' Introduction. British Dental Journal, 186, 60-63.

[10] Smith, B.G.N. and Knight, J.K. (1984) An Index for Measuring the Wear of Teeth. British Dental Journal, 156, 435-438. https://doi.org/10.1038/sj.bdj.4805394

[11] Famuyiwa, O.O. and Olorunshola, O.A. (1998) Some Family Factors in Sickle Cell Anaemia in Lagos, Nigeria. Nigerian Medical Practitioner, 35, 70-78.

[12] Slade, G.D., Nuttall, N., Sanders, A.E., Steele, J.G., Allen, P.F. and Lahti, S. (2005) Impacts of Oral Disorders in the United Kingdom and Australia. British Dental Journal, 198, 489-493. https://doi.org/10.1038/sj.bdj.4812252

[13] Lawal, F.B., Taiwo, J.O. and Arowojolu, M.O. (2014) How Valid Are the Psychometric Properties of the Oral? Health Impact Profile-14 Measure in Adult Dental Patients in Ibadan, Nigeria? Ethiopian Journal of Health Sciences; 24, 245-252. https://doi.org/10.4314/ejhs.v24i3.7 
[14] Kelleher, M. and Bishop, K. (1999) Tooth Surface Loss: An Overview. British Dental Journal, 186, 61-66. https://doi.org/10.1038/sj.bdj.4800020a2

[15] Litonjua, L.A., Andreana, S., Bush, P.J. and Cohen, R.E. (2003) Tooth Wear: Attrition, Erosion, and Abrasion. Quintessence International, 34, 435-446.

[16] Osborn-Smith, K.L., Burke, F.J. and Wilson, N.H. (1999) The Aetiology of the Non-Carious Cervical Lesion. International Dental Journal, 49, 139-143. https://doi.org/10.1002/j.1875-595X.1999.tb00898.x

[17] Imfeld, T. (1996) Dental Erosion. Definition, Classification and Links. European Journal of Oral Sciences, 104, 151-155. https://doi.org/10.1111/j.1600-0722.1996.tb00063.x

[18] Oginni, A.O. and Olusile, A.O. (2002) The Prevalence, Aetiology and Clinical Appearance of Tooth Wear: The Nigerian Experience. International Dental Journal, 52, 268-272. https://doi.org/10.1111/j.1875-595X.2002.tb00629.x

[19] Saerah, N.B., Ismail, N.M., Naing, L. and Ismail, A.R. (2006) Prevalence of Tooth Wear among 16-Year-Old Secondary School Children in Kota Bharu Kelantan. Archives of Orofacial Sciences, 1, 21-28.

[20] Taiwo, J.O., Ogunyinka, A., Onyeaso, C.O. and Dosumu, O.O. (2005) Tooth Wear in the Elderly Population in South East Local Government Area in Ibadan, Nigeria. Odontostomatol Trop, 28, 9-14.

[21] Rubb, N. (1991) Epidemiological Study of Tooth Wear. PhD Thesis, University of London, London.

[22] Al-Zarea, B.K. (2012) Tooth Surface Loss and Associated Risk Factor in Northern Saudi Arabia. ISRN Dentistry, 2012, Article ID: 161565.

https://doi.org/10.5402/2012/161565

[23] Smith, B.G. and Robb, N.D. (1996) The Prevalence of Tooth Wear in 1007 Dental Patients. Journal of Oral Rehabilitation, 23, 232-239. https://doi.org/10.1111/j.1365-2842.1996.tb00846.x

[24] Bardsley, P.F. (2008) The Evolution of Tooth Wear Indices. Clinical Oral Investigations, 12, 15-19. https://doi.org/10.1007/s00784-007-0184-2

[25] Ogunrinde, T.J. and Dosumu, O.O. (2012) The Influence of Demographic Factors and Medical Condition on Patient's Complaints with Complete Denture. Annals of Ibadan Postgraduate Medicine, 10, 16-21.

[26] Locker, D. (1992) The Burden of Oral Disorders in a Population of Older Adults. Community Dental Health, 9, 109-124.

[27] Vargas-Ferreira, F., Piosevan, C. and Praetzel, J.R. (2010) Tooth Erosion with Low Severity Does Not Impact Child Oral Health-Related Quality of Life. Caries Research, 44, 531-539. https://doi.org/10.1159/000321447

[28] Pires de Andrade, F.J., Sales-Peres, A.C., Moura-Grec, P.G., Abel Mapengo, M.A., Sales-Peres, A. and Sales-Peres, S.H. (2015) Nutritional Status, Tooth Wear and Quality of Life in Brazilian School Children. Public Health Nutrition, 19, 1479-1485. https://doi.org/10.1017/S1368980015002876 


\section{Appendix 1: Questionnaire}

This questionnaire is to assess the impact of tooth surface loss on the quality of life of patients seen in a Nigerian Teaching Hospital. Kindly provide honest answers based on your personal experience. The information you provide will be used for the above study without making any reference to you personally. (Are you willing to grant the interview? Yes No .............)

\section{Section A}

1) Age

2) Gender

3) Occupation

4) Level of education

5) Religion

6) For how long have you had problem with your tooth/teeth?

7) Teeth with tooth surface loss .......

8) Types of tooth surface loss............

\section{Section B}

What is your experienced in the last 6 months in regard to the following questions?

\begin{tabular}{cccc}
\hline OHIP questions & $\begin{array}{l}\text { Very } \\
\text { often }\end{array}$ & $\begin{array}{c}\text { Fairly } \\
\text { often }\end{array}$ & Occasionally Rarely Never \\
\hline
\end{tabular}

1) Have you had difficult chewing any food because of problem with your teeth?

2) Have you had trouble pronouncing any words because of problems with your teeth?

3) Has your sense of taste been affected by problems with your teeth?

4) Have you had painful aching anywhere

in your teeth?

5) Have you been self-conscious because of your teeth?

6) Have you felt tense because of problems with your teeth?

7) Has your diet been unsatisfactory because of problems with your teeth?

8) Have you had to interrupt meals because of problems with your teeth?

9) Have you found it difficult to relax because of problems with your teeth?

10) Have you been embarrassed because of your teeth?

11) Have you been a bit irritable with other people because of your teeth?

12) Have you had difficulty doing your usual jobs (or attending school) because of problems with your teeth?

13) Have you found life less satisfying because of problems with your teeth?

14) Have you been unable to perform the usual functions because of problems with your teeth? 